\title{
Engineering of magnetic properties in doped bismuth ferrite materials
}

\author{
Hamdan Akbar Notonegoro ${ }^{1,2}$, Bambang Soegijono ${ }^{1, a}$, Isom Mudzakir ${ }^{1}$ \\ ${ }^{1}$ Dept. of Physic, Universitas Indonesia, Depok 16424, Indonesia \\ ${ }^{2}$ Dept. of Mechanical Engineering, Universitas Sultan Ageng Tirtayasa, Cilegon 42435, Indonesia
}

\begin{abstract}
The engineering of magnetic behaviour of $\mathrm{Li} / \mathrm{Zn}$ doped $\mathrm{BiFeO}_{3}$ had been done by synthesized a polycrystalline of $\mathrm{BiFeO}_{3}$, $\mathrm{Bi}_{0.96} \mathrm{Li}_{0.02} \mathrm{FeO}_{3}$, and $\mathrm{Bi}_{0.95} \mathrm{Zn}_{0.05} \mathrm{FeO}_{3}$. Investigation of crystallite structure and magnetic properties of the sampel had been done by X-ray diffraction and VSM analysis. At room temperature, the lithium and zinc doped bismuth ferrite has conducted a different magnetic behaviour. Within the ferromagnetic region, an increases of magnetic saturation or enlarger magnetic coercivity were identified. Doping lithium resulted in increasing magnetic saturation $\left(M_{s}\right)$ and magnetic remanent $\left(M_{r}\right)$, significantly. Meanwhile, doping zinc resulted in enlarger of magnetic coercivity coincide with the reveal of $\mathrm{Bi}_{20} \mathrm{FeO}_{40}$ as the second phase.
\end{abstract}

\section{Intoduction}

Bismuth ferrite or $\mathrm{BiFeO}_{3}$ (BFO) become the most studied materials due its wide range of physical properties which promises for many applications [1]. Ferroelectric $\left(\mathrm{T}_{\mathrm{C}}=830^{\circ} \mathrm{C}\right)$ and antiferromagnetic $\left(\mathrm{T}_{\mathrm{N}}=370{ }^{\circ} \mathrm{C}\right)$ ordering above room temperature, were devoted many researchers to understand and tailor these physical properties to fulfil the requirement of specific technology applications, i.e. multiferroic.

One of the vital engineerings on the multiferroic application is the enhancement of magnetic properties. Many works have been done to enlighten the role of doping towards the magnetic properties of BFO. Different types of doping can be rising the magnetic moment of BFO, while the reduction size of BFO was also increased by the magnetic moment [2]-[4]. Du et.al. [5] found that the La-doped BFO in Bi-site caused the effect of lattice parameter increases which resulted in increasing of magnetic moment. In common, Khomchenko et. al.[6] have reported that Sm-doped BFO in Bi-site was significantly enhanced for the spontaneous magnetization, while the phase transition from a rhombohedral to an orthorhombic was conducted by the composition. On the other hand, $\mathrm{Zn}$ or Li-doped BFO into Fe-site can significantly be enhanced the magnetic saturation of BFO by the effect of crystallinity improved or particle-size reduction, have been reported [7], [8]. Recently, Baqiah et. al. [9] have reported that $\mathrm{BiTiO}_{3}$ phase content incorporation with the BFO matrix tends to increase the magnetic saturation [10].

\footnotetext{
${ }^{\text {a }}$ Corresponding author : naufal@ui.ac.id
} 
Hence, it is interesting to engineering the magnetization of doping BFO. Different doping-site and different type of materials affect the complexity of magnetic behavior in BFO [11]. The increases in magnetic coercivity or magnetic saturation have different benefits and applications [12], [13]. In order to synthesize doped BFO, there are several preparations technique such as hydrothermal, solid-state reaction, co-precipitation, and solgel [5], [8], [14], [15]. Of all these processes, a sol-gel technique has been widely used because of its easy, straight-forward and its final product is highly pure [7], [16]. Moreover, this technique produces an ultrafine porous powder uniformly which can be accommodating industrial-scale production.

This paper aimed to perform engineering of magnetic behavior in low content $\mathrm{Li} / \mathrm{Zn}$ doped BFO. To further understand by XRD and VSM analyze, the polycrystalline sample of $\mathrm{BiFeO}_{3}, \mathrm{Bi}_{0.96} \mathrm{Li}_{0.02} \mathrm{FeO}_{3}$, and $\mathrm{Bi}_{0.95} \mathrm{Zn}_{0.05} \mathrm{FeO}_{3}$ were synthesized through a sol-gel route. The phase present and magnetic behavior of the sample is assessed.

\section{Experimental procedures}

\subsection{Sample preparation}

Polycrystalline samples of $\mathrm{BiFeO}_{3} \quad$ (BFO), $\mathrm{Bi}_{0.96} \mathrm{Li}_{0.02} \mathrm{FeO}_{3} \quad$ (BLFO), and $\mathrm{Bi}_{0.95} \mathrm{Zn}_{0.05} \mathrm{FeO}_{3}$ (BFO-Z) with a low content $\mathrm{Li} / \mathrm{Zn}$ were synthesized via a sol-gel method. All the nitric salt and acetic salt were purchased from Sigma Aldrich and Merck with $\geq 99.5 \%$ purity. Proportional wt $\%$ amounts of $\mathrm{Fe}\left(\mathrm{NO}_{3}\right)_{3} \cdot 9 \mathrm{H}_{2} \mathrm{O}, \mathrm{Bi}\left(\mathrm{NO}_{3}\right)_{3} \cdot 5 \mathrm{H}_{2} \mathrm{O}$, $\mathrm{CH}_{3} \mathrm{COOLi} \cdot 2 \mathrm{H}_{2} \mathrm{O}$ and $\mathrm{Zn}$ granule (which dissolved with $5 \mathrm{ml}$ of concentrated nitric acid) were weighed and dissolved in $200 \mathrm{ml}$ of de-ionized water in a glass beaker. Then, citric acid (3:1 citric acid and metal ratio) was added as a chelating agent. These solutions were mixed and heated at $80{ }^{\circ} \mathrm{C}$ with constant stirring until it becomes a very thick gel, then dried in an oven at $120{ }^{\circ} \mathrm{C}$ for $24 \mathrm{~h}$ to be xerogel. During the drying process, keep it from the impurity or uncontrolled combustion. After that the xerogel was collected, ground and heated at $600-750{ }^{\circ} \mathrm{C}$ for $5 \mathrm{~h}$. Finally, all the samples were ground.

\subsection{Characterization}

In order to characterize the phase present and the structure of that phase in the sample, powder XRD data were collected on the PANanalytical Diffractometer (Model: X'Pert Pro) in the diffraction range of $20^{\circ}-70^{\circ}$. Magnetic hysteresis measurements in the room temperature $\left(27^{\circ} \mathrm{C}-300 \mathrm{~K}\right)$ and fields range of $0-1.4 \mathrm{~T}$ were performed using a vibrating sample magnetometer (VSM) to identify the magnetic behavior established in each sample.

\section{Result and discussion}

\subsection{Structure of the sample}

The summary of our XRD results is shown in Figure 1. The amounts of BFO phase present in all the samples and their corresponding lattice parameters were analyzed and calculated by Rietveld method using X'Pert HighScore plus software with ICSD 98-0181983 as a reference database (see Table 1). The XRD patterns confirm the presence of strong (012), (104), (110), (202), (024), (214) peaks in all samples. These peak pattern were consistent with the BFO phase structure (rhombohedral structure system with space group R3c) from the previous investigations [3], [4]. The XRD obtained for the BFO and BLFO 
compound were indexed with lattice parameters $a=b=5.580 \AA$ and $c=13.874 \AA$, as mentioned in Table 1. However, doping $\mathrm{Zn}$ into Bi-site in BFO-Z were causes the lattice parameter declined because the atomic radius of $\mathrm{Zn}(142 \mathrm{pm})$ is smaller than that $\mathrm{Bi}$ atom (143pm). This content had resulted in the decrease of lattice parameters with $a=b=5.576$ $\AA$ and $c=13.863 \AA$, comparing to $\mathrm{BiFeO}_{3}$ sample (see Table 1). These occasion coincided with the reveal of $\mathrm{Bi}_{20} \mathrm{FeO}_{40}$ (reference: ICSD 98-004-1937) which is cubic structure and space groups I23, as the second phase accompanying the BFO phase present in BFO-Z sample (Figure 1).

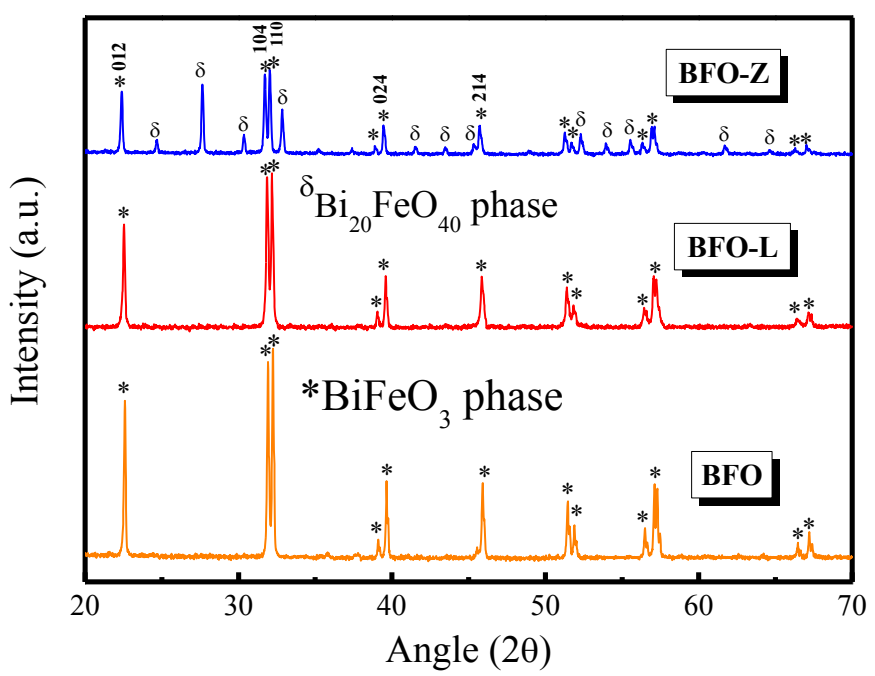

Figure 1. $\mathrm{XRD}$ pattern of $\mathrm{BiFeO}_{3}(\mathrm{BFO}), \mathrm{Bi}_{0.96} \mathrm{Li}_{0.02} \mathrm{FeO}_{3}$ (BFO-L), and $\mathrm{Bi}_{0.95} \mathrm{Zn}_{0.05} \mathrm{FeO}_{3}$ (BFO-Z). All peaks patterns of $\mathrm{BFO}$ phase in all samples were consistent with rhombohedral structure with space group R3c.

Table 1. Lattice parameters and percentage of $\mathrm{BiFeO}_{3}$ phase present in $\mathrm{BiFeO}_{3}, \mathrm{Bi}_{0.96} \mathrm{Li}_{0.02} \mathrm{FeO}_{3}$, and $\mathrm{Bi}_{0.95} \mathrm{Zn}_{0.05} \mathrm{FeO}_{3}$.

\begin{tabular}{|l|r|r|r|}
\hline \multirow{2}{*}{ Parameter } & \multicolumn{3}{|c|}{ Sample } \\
\cline { 2 - 4 } & \multicolumn{1}{|c|}{ BFO } & \multicolumn{1}{|c|}{ BFO-L } & \multicolumn{1}{c|}{ BFO-Z } \\
\hline$a=b(\AA)$ & 5.580 & 5.580 & 5.576 \\
\hline$c(\AA)$ & 13.874 & 13.874 & 13.863 \\
\hline$V\left(\AA^{3}\right)$ & 374.157 & 374.109 & 373.318 \\
\hline$\rho\left(\mathrm{g} \mathrm{cm}^{-3}\right)$ & 8.330 & 8.330 & 8.350 \\
\hline$D(\mathrm{~nm})$ & 193.870 & 73.840 & 136.930 \\
\hline Micro strain $(\%)$ & 0.017 & 0.114 & 0.038 \\
\hline BiFeO $_{3}(\%)$ & 100.0 & 100.0 & 63.5 \\
\hline$B i_{25} \mathrm{FeO} 40(\%)$ & 0.0 & 0.0 & 36.5 \\
\hline$R_{w p}(\%)$ & 4.878 & 4.71 & 6.530 \\
\hline$G O F$ & 1.599 & 1.372 & 1.380 \\
\hline
\end{tabular}

In our circumstance, the refinement goodness of fit $(G O F)$ parameters of all sample were $<1.6$ with $R$-factors not more than $7(<10)$. As mentioned in Table 1 , a broad peaks of the powder XRD sample is due to the crystallite size of BFO phase. Scherrer formula was used to calculate the crystallite size $(D)$ of the BFO nanoparticles, 


$$
D=\frac{0.9 \lambda}{\beta \cos \theta}
$$

where $\lambda$ is the wavelength of $\mathrm{Cu}-\mathrm{K} \alpha$ radiation, and $B$ is them full-width at half-maximum (FWHM). Nevertheles, the $B$-unit should be converted into radian. We found that the crystallite size of our sample is varied $(193.87 \mathrm{~nm}, 73.840 \mathrm{~nm}$, and $136.930 \mathrm{~nm})$ which may be caused by particles coagulation.

Three dimensional of $\mathrm{BiFeO}_{3}$ and $\mathrm{Bi}_{25} \mathrm{FeO}_{40}$ phase structure were illustrated from refinement data results using VESTA software as shown in Figure 2. From the picture, we can be seen the oxygen atoms were forming a polyhedral shape with the $\mathrm{Fe}$-atom as the center. On the $\mathrm{BiFeO}_{3}$ phase structure, we can see that doping Li can replace some of $\mathrm{Bi}$ site precisely. Meanwhile, we can see in the $\mathrm{Bi}_{25} \mathrm{FeO}_{40}$ phase structure that $\mathrm{Bi}$-atom arranged polyhedral shape much more than the Fe-atom.

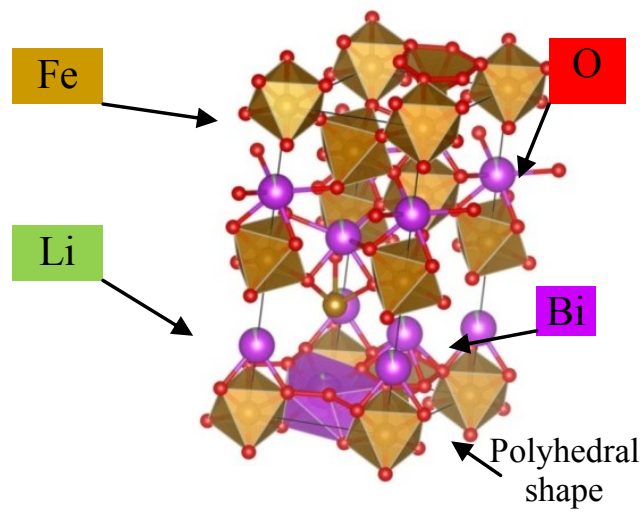

(a)

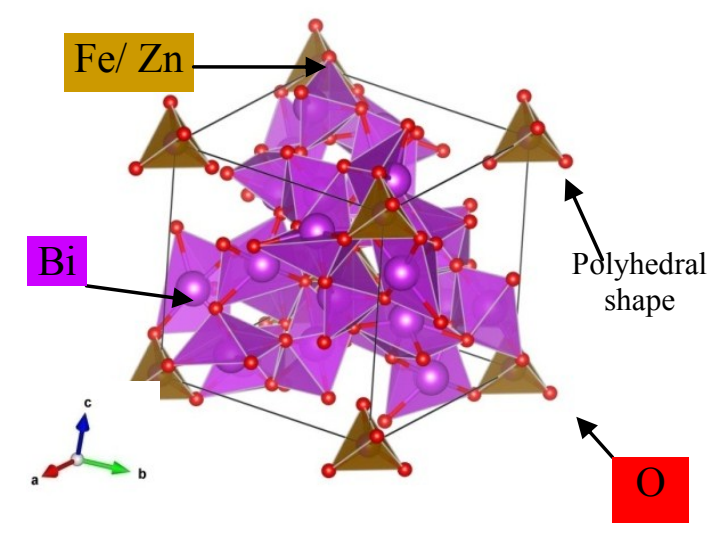

(b)

Figure 2. Three dimensional of two phase present in the sample, a) $\mathrm{BiFeO}_{3}$ phase structure and, b) $\mathrm{Bi}_{25} \mathrm{FeO}_{40}$ phase structure. In bismuth ferrite structure, Li could replaced on Bi-site well. On the other side, the Fe-site in the $\mathrm{Bi}_{25} \mathrm{FeO}_{40}$ structure could replaced by $\mathrm{Zn}$ atom, alternately.

\subsection{Magnetic properties}

Figure 3 shows room temperature hysteresis loops of BFO, BFO-L, and BFO-Z samples, respectively. There are some factors that can affect the magnetic behavior of all sample such as distortion of crystallite size. The saturation magnetization $\left(M_{s}\right)$, coercivity $\left(H_{c}\right)$, and remanence magnetization $\left(M_{r}\right)$ of all samples are mentioned in Table 2.

The BFO and BFO-Z sample shows a low saturated hysteresis loop $M_{s}(0.08 \mathrm{emu} / \mathrm{g}$ and $0.14 \mathrm{emu} / \mathrm{g}$, respectively) which is $M_{r}$ of both samples is identical value $(0.02 \mathrm{emu} / \mathrm{g})$. In comparison, the $M_{s}$ of BFO-L is the larger $(4.89 \mathrm{emu} / \mathrm{g})$ more than BFO and BFO-Z with the $M_{r}$ is become $1.42 \mathrm{emu} / \mathrm{g}$, as compensate for the $\mathrm{Li}$ present in the structure. Refer to Table 1, the increment of $M_{s}$ in BFO-L and BFO-Z were inline with the increment of micro strain percent value of both sample, compare to $\mathrm{BFO}$ value. Contigously, the present of $\mathrm{Zn}$ in BFO-Z sample subtituting on the Bi-site had broaden the $H_{c}$ value larger than two others sample, BFO and BFO-L which both samples have a closed coercivity value. Further, the broaden of $H_{c}$ value in BFO-Z is associated with the rising of atomic density and the reveal of $\mathrm{Bi}_{20} \mathrm{FeO}_{40}$ phase structure incorporated with the $\mathrm{BFO}$ phase present. This change associated with the increment of stored magnetic energy during hysteresis circle. 


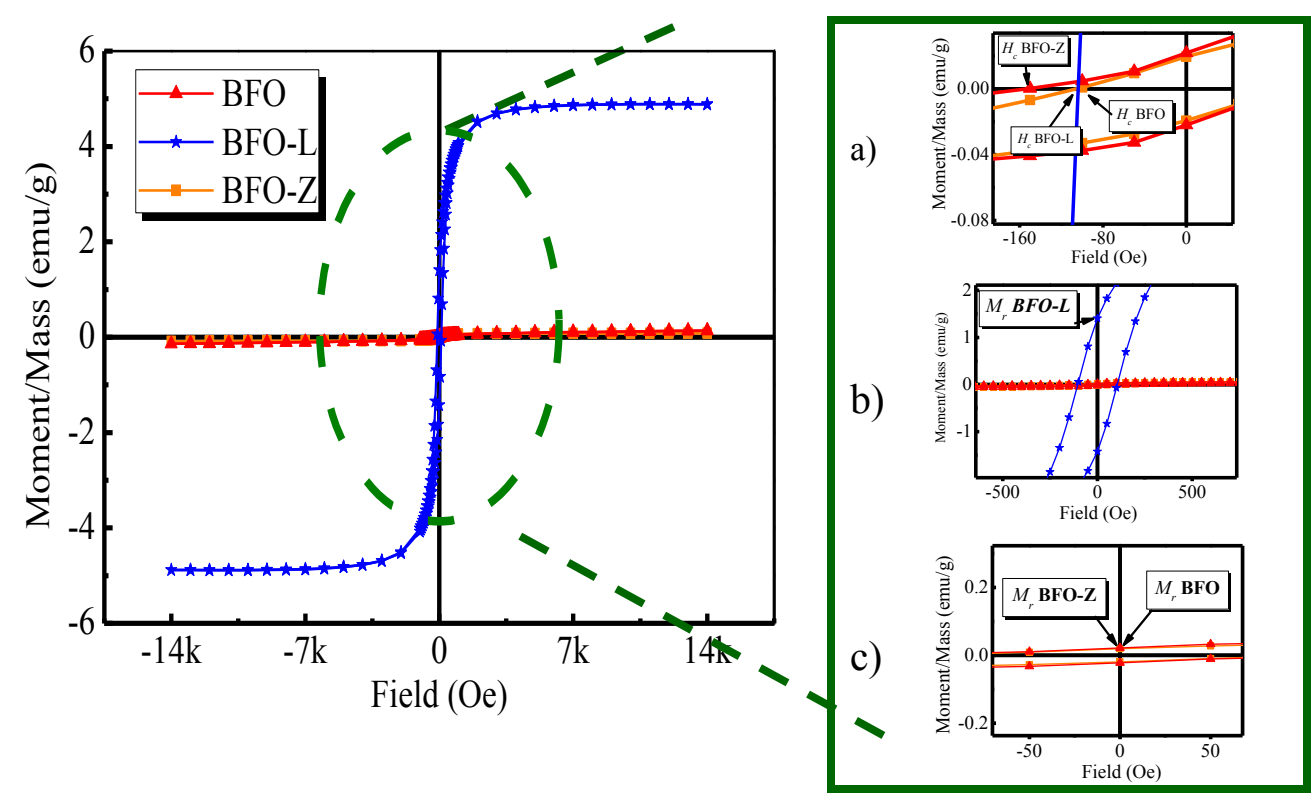

Figure 3. Magnetic properties of BFO, BFO-L, and BFO-Z samples: a) Magnetic Coercivity $\left(H_{c}\right)$ of all the samples, b) magnetic remanent $\left(M_{r}\right)$ of BFO-L sample, c) $M_{r}$ of BFO and BFO-Z samples.

Table 2 The magnetic saturation (Ms), coercivity (Hc), and remanence magnetization (Mr) of BFO, BFO-L, and BFO-Z samples.

\begin{tabular}{|l|r|r|r|}
\hline \multirow{2}{*}{ Parameter } & \multicolumn{3}{|c|}{ Sample } \\
\cline { 2 - 4 } & \multicolumn{1}{|c|}{ BFO } & \multicolumn{1}{c|}{ BFO-L } & \multicolumn{1}{c|}{ BFO-Z } \\
\hline$M_{s}(\mathrm{emu} / \mathrm{g})$ & 0.08 & 4.89 & 0.14 \\
\hline$M_{r}(\mathrm{emu} / \mathrm{g})$ & 0.02 & 1.42 & 0.02 \\
\hline$H_{c}(\mathrm{Oe})$ & 105.39 & 104.24 & 152.18 \\
\hline
\end{tabular}

\section{Conclusion}

The BFO, BFO-L, and BFO-Z samples were synthesized by the sol-gel process for engineering the magnetic behavior of that sample. All the samples were crystalized in rhombohedral with space group $\mathrm{R} 3 \mathrm{c}$, precisely. The lattice parameters of $\mathrm{BiFeO}_{3}$ in $\mathrm{BFO}$ and $\mathrm{BFO}-\mathrm{L}$ samples exhibit identical value, while the lattice parameters of $\mathrm{BiFeO}_{3}$ phase decreased with doping of $\mathrm{Zn}$ content. The magnetic saturation and magnetic remanent increased with doping $\mathrm{Li}$. Further, magnetic coercivity broadens coincide with the reveal of $\mathrm{Bi}_{25} \mathrm{FeO}_{40}$ phase structure after doping $\mathrm{Zn}$ in the sample. With this results, the behavior of magnetic properties in bismuth ferrite had been successfully engineered.

\section{Acknowledgement}

The author acknowledge with gratitude the financial support from the Ministry of Research, Technology and Higher Education of Indonesia (RISTEK-DIKTI), under grant Penelitian Dasar Unggulan Perguruan Tinggi (PDUPT), No. 366/UN2.R3.1/HKP05.00/2018). 


\section{References}

1. R. A. M. A. M. Gotardo et al., "Improved magnetic properties and structural characterizations in Mn doped 0.9BiFeO3-0.1BaTiO3 compositions," Scr. Mater., vol. 130, pp. 161-164, 2017.

2. S. Zheng, J. Wang, J. Zhang, H. Ge, Z. Chen, and Y. F. Gao, "The structure and magnetic properties of pure single phase $\mathrm{BiFeO} 3$ nanoparticles by microwaveassisted sol-gel method," J. Alloys Compd., vol. 735, pp. 945-949, 2018.

3. S. Godara, N. Sinha, G. Ray, and B. Kumar, "Combined structural, electrical, magnetic and optical characterization of bismuth ferrite nanoparticles synthesized by auto-combustion route," J. Asian Ceram. Soc., vol. 2, no. 4, pp. 416-421, 2014.

4. M. Kumar, K. L. Yadav, and G. D. Varma, "Large magnetization and weak polarization in sol-gel derived BiFeO3ceramics," Mater. Lett., vol. 62, no. 8-9, pp. 1159-1161, 2008.

5. Y. Du, Z. X. Cheng, M. Shahbazi, E. W. Collings, S. X. Dou, and X. L. Wang, "Enhancement of ferromagnetic and dielectric properties in lanthanum doped BiFeO3 by hydrothermal synthesis," J. Alloys Compd., vol. 490, no. 1-2, pp. 637$641,2010$.

6. V. A. Khomchenko et al., "Effect of Sm substitution on ferroelectric and magnetic properties of BiFeO3," Scr. Mater., vol. 62, no. 5, pp. 238-241, 2010.

7. J. Liu et al., "Influence of Zn doping on structural , optical and magnetic properties of BiFeO 3 fi lms fabricated by the sol - gel technique," Mater. Lett., vol. 133, pp. 49-52, 2014.

8. A. Billah, "INVESTIGATION OF MULTIFERROIC AND PHOTOCATALYTIC PROPERTIES OF Li DOPED BiFeO3 NANOPARTICLES By," Bangladesh University of Engineering and Technology, 2017.

9. H. Baqiah, Z. A. Talib, A. H. Shaari, N. Tamchek, and N. B. Ibrahim, "Synthesis, optical and magnetic behavior of $(\mathrm{BiFeO} 3) 1-\mathrm{x}(\alpha-\mathrm{Fe} 2 \mathrm{O} 3) \mathrm{x}$ nanocomposites," Mater. Sci. Eng. B, vol. 231, no. August 2017, pp. 5-10, 2018.

10. H. Liu, Y. Guo, B. Guo, and D. Zhang, "nanopowders by a sol e gel method," vol. 19, pp. 69-72, 2013.

11. Q. Rong, W. Xiao, G. Xiao, A. Hu, and L. Wang, "Magnetic properties in BiFeO3 doped with $\mathrm{Cu}$ and $\mathrm{Zn}$ first-principles investigation," J. Alloys Compd., vol. 674, pp. 463-469, 2016.

12. V. Iurchuk, B. Doudin, J. Bran, and B. Kundys, "Electrical Writing of Magnetic and Resistive Multistates in CoFe Films Deposited onto Pb[ZrxTi1-x]O3," Phys. Procedia, vol. 75, pp. 956-966, 2015.

13. B. Ramachandran and M. S. R. Rao, "Low temperature magnetocaloric effect in polycrystalline BiFeO3 ceramics,” Appl. Phys. Lett., vol. 95, no. 14, pp. 20072010, 2009.

14. M. Guo et al., "Enhancement of multiferroic properties in Bi0.92Ho0.08Fe0.97Mn0.03O3/ Zn0.5Ni0.5Fe2O4 bilayered thin films by tunable schottky barrier and interface barrier," J. Alloys Compd., vol. 741, pp. 420-431, 2018.

15. V. Kumar and S. Singh, "Optical and magnetic properties of ( 1-x ) BiFeO 3 xCaTiO 3 nanoparticles," vol. 732, pp. 350-357, 2018.

16. R. Safi and H. Shokrollahi, "Physics, chemistry and synthesis methods of nanostructured bismuth ferrite $(\mathrm{BiFeO} 3)$ as a ferroelectro-magnetic material," Prog. Solid State Chem., vol. 40, no. 1-2, pp. 6-15, 2012. 